\title{
Meningomyeloencephalitis secondary to Mycobacterium haemophilum infection in AIDS
}

\author{
Sandra Leskinen ${ }^{1}$, Xena Flowers ${ }^{1}$, Katharina Thoene ${ }^{2}$, Anne-Catrin Uhlemann ${ }^{2,3}$, James E. Goldman ${ }^{1}$ and \\ Richard A. Hickman ${ }^{1 *}$ (D)
}

\begin{abstract}
Infections by opportunistic non-tuberculous mycobacteria (NTM) are rising in global incidence. One emerging, slowly growing NTM is Mycobacterium haemophilum, which can cause skin, lung, bone, and soft tissue infections in immunocompromised patients as well as lymphadenitis in immunocompetent individuals. Detection of this microorganism is difficult using conventional culture-based methods and few reports have documented involvement of this pathogen within the central nervous system (CNS).

We describe the neuropathologic autopsy findings of a 39-year-old man with AIDS who died secondary to $M$. haemophilum CNS infection. He initially presented with repeated bouts of pyrexia, nausea and vomiting, and altered mental status that required numerous hospitalizations. CSF infectious workups were consistently negative. His most recent admission identified hyperintensities within the brainstem by MRI and despite antibiotic therapies for suspected CNS infection, he died. Autopsy revealed a swollen brain with marked widening of the brainstem. Microscopic examination of the brain and spinal cord showed focal lymphohistiocytic infiltrates, gliosis and neuronal loss that were associated with acid-fast bacilli (AFB). The brainstem was the most severely damaged and AFB were found to congregate along arterial territories lending support to the notion of hematogenous spread as a mechanism for the organisms' dissemination. 16S rRNA sequencing on formalin-fixed paraffin-embedded tissue enabled post-mortem identification of M. haemophilum. This sequencing methodology may permit diagnosis on CSF intra-vitam.
\end{abstract}

Keywords: Mycobacterium haemophilum, Non-tuberculous mycobacteria, HIV, AIDS, Rhomboencephalitis, Meningomyeloencephalitis

\section{Introduction}

Non-tuberculous mycobacterial (NTM) infections are generally seen in patients with impaired cell-mediated immunity but can also be found in patients without underlying disease [1]. Included in this category of NTM is Mycobacterium haemophilum, which is a slowgrowing, acid-fast bacillus that is recognized to cause cutaneous, pulmonary, bone, and joint infections [2, 3].

\footnotetext{
* Correspondence: rh2850@cumc.columbia.edu

'Department of Pathology \& Cell Biology, Columbia University Irving Medical Center, New York, NY 10032, USA

Full list of author information is available at the end of the article
}

This bacterium can infect immunocompromised patients and transplant recipients but may also affect immunocompetent individuals as a cause for cervical lymphadenitis (scrofula) [4-6]. M. haemophilum infection within the central nervous system (CNS) is rare and, to our knowledge, only six reports in the English literature have described the neuropathologic findings of the infection, all of which are based on surgical biopsy material [713]. This underreporting may relate to the inherent challenges of culturing this organism using conventional microbiological methods [3]. We describe the postmortem neuropathologic findings of an AIDS patient

(c) The Author(s). 2020 Open Access This article is licensed under a Creative Commons Attribution 4.0 International License, which permits use, sharing, adaptation, distribution and reproduction in any medium or format, as long as you give appropriate credit to the original author(s) and the source, provide a link to the Creative Commons licence, and indicate if changes were made. The images or other third party material in this article are included in the article's Creative Commons licence, unless indicated otherwise in a credit line to the material. If material is not included in the article's Creative Commons licence and your intended use is not permitted by statutory regulation or exceeds the permitted use, you will need to obtain permission directly from the copyright holder. To view a copy of this licence, visit http://creativecommons.org/licenses/by/4.0/ The Creative Commons Public Domain Dedication waiver (http://creativecommons.org/publicdomain/zero/1.0/) applies to the data made available in this article, unless otherwise stated in a credit line to the data. 
with meningomyeloencephalitis as a result of M. haemophilum infection. Speciation of the microorganism was only rendered after death by using $16 \mathrm{~S}$ rRNA sequencing on the formalin-fixed, paraffin-embedded tissue. The histopathology and pattern of distribution of the microorganism are discussed.

\section{Case presentation}

The decedent was a 39-year-old man with newly diagnosed HIV/AIDS, who had recurrent bouts of pyrexia of unknown origin, nausea and vomiting, and altered mental status that required repeated admissions at an outside hospital over a four-month period. Aside from the recent diagnosis of HIV/AIDS, there was no other significant past medical history. Assessment of his respiratory system showed no abnormalities and chest radiographs showed no focal consolidation, atelectasis, or pleural fluid accumulation. Microbiological analysis of cerebrospinal fluid was negative for infectious organisms. On his last admission, cranial imaging identified a brainstem mass and the patient was transferred to our neurological intensive care unit requiring intubation for suspected aspiration pneumonia. At the time of transfer, his CD4 cell count was 3 cells $/ \mathrm{mm}^{3}$ with a viral load of 46,000 copies $/ \mathrm{mL}$ and he was initiated on antiretroviral therapy (ART). He underwent MRI which showed a new nodular brainstem enhancement and residual leptomeningeal enhancement (Fig. 1a) in addition to a $7 \mathrm{~mm}$ enhancing region at the cervicomedullary junction in the anterior cervical spinal cord. Analysis of his cerebrospinal fluid (CSF) at this time showed an elevated protein $(97 \mathrm{mg} / \mathrm{dL}$; normal: $15-45$ $\mathrm{mg} / \mathrm{dL})$ and glucose $(80 \mathrm{mg} / \mathrm{dL}$; normal: $40-70 \mathrm{mg} / \mathrm{dL})$ with a lymphocytosis $\left(100\right.$ cells $\left./ \mathrm{mm}^{3}\right)$. Quantitative PCR was negative for JC virus and a meningitis/encephalitis PCR panel was negative for Escherichia coli, Haemophilus influenzae, Listeria monocytogenes, Neisseria meningitidis,
Streptococcus pneumoniae, Cytomegalovirus, Enterovirus, Human Herpes Virus-6, Herpes Simplex Virus-1, Herpes Simplex Virus-2, Human Parechovirus, Varicella Zoster Virus, and Cryptococcus neoformans. Furthermore, culture of CSF, including cultures for acid-fast bacilli (AFB), showed no growth of microorganisms. Despite broadspectrum antibiotics for suspected rhomboencephalitis, he died. Other than his known HIV status, at no point during his hospitalizations was an infectious agent identified.

An autopsy restricted to the brain and spinal cord was performed with written informed consent obtained from the family. The fresh brain weight was increased (1525 g) and the leptomeninges were thickened multifocally, being most pronounced over the midbrain, pons, and right middle cerebellar peduncle. The brainstem was diffusely widened (Fig. 1b) and the cerebral gyri were swollen. Coronal sections of the cerebral hemispheres revealed marked, bilateral dilatation of the lateral and third ventricles. Transverse sections of the brainstem showed poor demarcation of the gray and white matter (Fig. 1c-h). The substantia nigra was pale and the cerebral aqueduct was obliterated (Fig. 1c). The pons and medulla oblongata appeared mottled and hyperemic with white patches over the basis pontis (Fig. 1d-h).

Microscopically, leptomeningeal lymphohistiocytic infiltrates were seen multifocally. Widespread damage was seen in the brain and spinal cord with focal lymphohistiocytic infiltrates, neuropil vacuolation, neuronal loss, gliosis, and perivascular inflammation. This was found throughout the examined neocortex with relative sparing of the corpus striatum and thalamus. The subcortical white matter showed patches of myelin pallor and were also associated with lymphohistiocytic inflammation.

The most severe damage in the CNS involved the brainstem. The degree of injury in the brainstem was not diffuse but varied throughout. In the midbrain, at
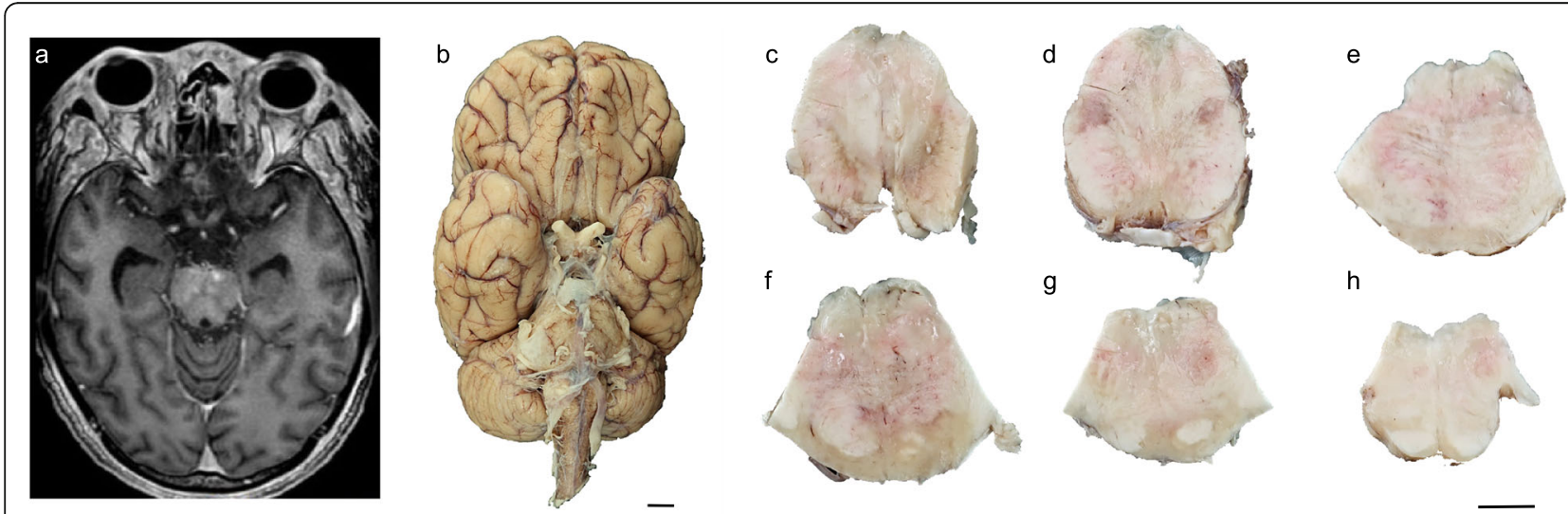

Fig. 1 Radiologic and macroscopic autopsy findings of this patient. a T1 FLAIR weighted MRI showing multiple hyperintensities within the upper pons. $\mathbf{b}$ Inferior aspect of the brain demonstrating a markedly widened brainstem. $\mathbf{c}-\mathbf{h}$ Transverse sections of the brainstem from rostral to caudal commencing from the caudal midbrain to the rostral medulla oblongata. Scale bars: $\mathbf{b}, 1 \mathrm{~cm} ; \mathbf{c}-\mathbf{h}, 1 \mathrm{~cm}$. The high resolution source of Figure 1 is available as Additional file 1 
the level of the decussation of the superior cerebellar peduncles (Fig. 2g), the most dramatic inflammatory infiltrate was in the midline and extended laterally to involve the substantia nigra (Fig. 2g-h). The substantia nigra showed marked neuronal loss and was associated with neuromelanin-laden macrophages (Fig. 2k). Gram,

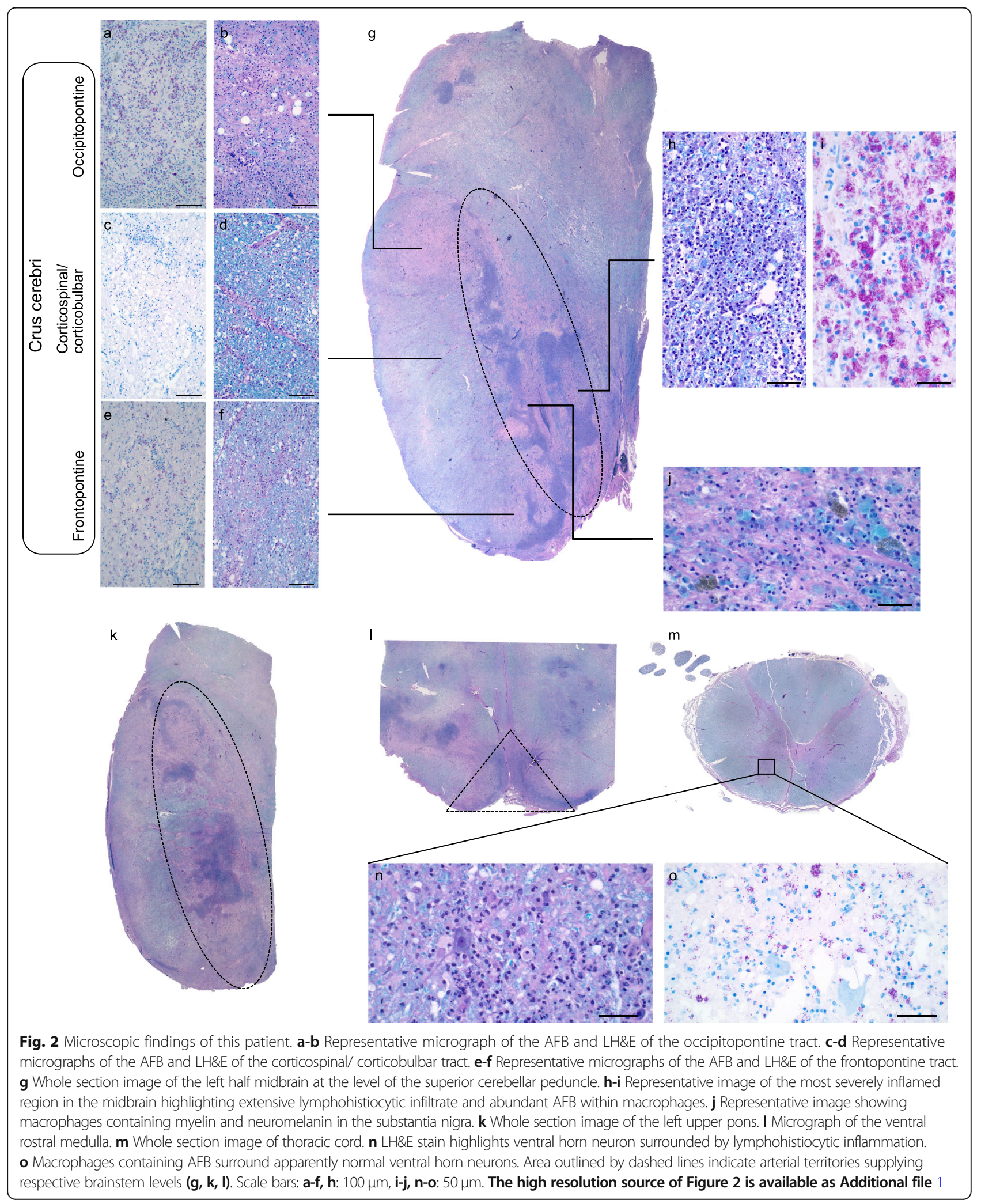


periodic acid-Schiff (PAS) and Grocott's methenamine silver (GMS) stains were negative for organisms. AFB stains revealed numerous rod-shaped microorganisms within epithelioid histiocytes, thus compatible with NTM infection. The severely damaged midbrain harbored the highest density of AFB (Fig. 2i).

To determine the species of the AFB, DNA was extracted from formalin-fixed, paraffin-embedded material of the midbrain (ReliaPrep FFPE gDNA Miniprep System, Zymo). Using primers targeting the 16S V3-V4 rRNA region, DNA was amplified and Sanger sequencing was performed. Using BLAST searching on NCBI, the sequence matched closest to a group of nontuberculous mycobacterial references sequences, including M. haemophilum and M. riyadhense at 99\% identity. Therefore, the mycobacterial hsp65 protein gene region was amplified with the forward primer (5' ACCAAC GATGGTGTGTCCAT $3^{\prime}$ ) and the reverse primer (5' CTTGTCGAACCGCATACCCT 3') [14]. The obtained hsp65 sequence ranked highest with $99.72 \%$ identity to M. haemophilum.

\section{Discussion and conclusion}

Several histologic findings provide clues into the pathophysiology of this infection. Firstly, the density of AFB correlated with the degree of parenchymal damage. This gradient of injury and AFB density was evident in the crus cerebri. The most severe myelin loss was seen in the occipitopontine tract, which had the greatest density of AFB, whereas fewer AFB were present in the more preserved corticospinal tract (Fig. 2a-f). Secondly, the distribution of AFB followed arterial territories. At the level of the midbrain and pons, the density of AFB was highest along the territory of the paramedian branch of the basilar artery while at the rostral medulla oblongata, it followed the anterior spinal artery (Dashed outline of Fig. 2g, k, l). Chronic inflammation was also seen within the anterior horns of the spinal cord, which is also a territory of the anterior spinal artery (Fig. 2n-o) and showed formation of microglial nodules and abundant AFB.

The arterial distribution of damage supports the concept of hematogenous seeding from a non-CNS source. NTM are thought to reach the CNS via hematogenous spread from the gastrointestinal tract or the lungs [15]. The autopsy was CNS-restricted and so unfortunately identification of an extra-CNS origin could not be ascertained. In immunocompromised patients, M. haemophilum most commonly infects the skin, while pulmonary, bone, and joint infections are less frequent systems of involvement $[6,16]$. Aside from concerns of an aspiration pneumonia later in the patient's course, there were no pulmonary, dermatologic, or joint complaints documented during his clinical course. However, the possibility remains that a focal, cutaneous infection may have gone undetected. It is also uncertain as to the source of infection for this patient since little is known of the environmental habitat in which M. haemophilum dwells. Potential sources of $M$. haemophilum infection include drinking water, contact with certain animals, as well as exposure to cosmetics $[2,7,17,18]$.

In contrast to one prior surgical report of a single granulomatous mass secondary to M. haemophilum, the meningomyeloencephalitis did not show evidence of granulomata, emphasizing that this disease can have variation in clinical presentations and histopathologic findings [7]. Conventional culture methods that apply for other mycobacteria do not generally succeed with $M$. haemophilum. Identification of this fastidious organism requires a strong index of suspicion, needing iron-supplemented media and culturing at cooler temperatures $\left(30-32{ }^{\circ} \mathrm{C}\right)$ [19]. These necessary temperatures for optimal growth have been suggested as to why the organism favors infection in distal limb sites [20]. 16S rRNA sequencing is another method of identification and was critical in this challenging post-mortem diagnosis. In circumstances of suspected culture-negative meningoencephalitis, $16 \mathrm{~S}$ rRNA sequencing of CSF may be another useful diagnostic tool in accurately identifying $M$. haemophilum for better informed clinical care $[21,22]$.

\section{Supplementary information}

Supplementary information accompanies this paper at https://doi.org/10. 1186/s40478-020-00937-2.

Additional file 1. High resolution source for Figures $1 \& 2$

\section{Abbreviations}

AFB: Acid fast bacillus; ART: Anti-retroviral therapy; CNS: Central Nervous System; CSF: Cerebrospinal fluid; GMS: Grocott's methenamine silver; LH\&E: Luxol fast blue counterstained with hematoxylin and eosin; NTM: Nontuberculous mycobacterium; PAS: Periodic acid-Schiff and (GMS)

Authors' contributions

RAH and JEG were involved in the pathological assessment. KT and ACU performed and interpreted the microbiome analysis. SL, XEF, and RAH drafted the manuscript. All authors read and approved the final manuscript.

Availability of data and materials N/A.

Ethics approval and consent to participate

This study was exempt from approval by the institutional review board, as this is not a research study. Written consent from the next of kin was obtained for publication of this report.

\section{Competing interests}

None declared.

\section{Author details}

'Department of Pathology \& Cell Biology, Columbia University Irving Medical Center, New York, NY 10032, USA. ${ }^{2}$ Department of Medicine, Columbia University Irving Medical Center, New York, NY 10032, USA. ${ }^{3}$ Microbiome \& Pathogen Genomics Core, Columbia University Irving Medical Center, New York, NY 10032, USA. 
Received: 28 March 2020 Accepted: 22 April 2020

Published online: 19 May 2020

\section{References}

1. Cegielski JP, Wallace RJ Jr (1997) Central nervous system infections with nontuberculous mycobacteria. Clin Infect Dis 25:1496-1497

2. Lindeboom JA, Bruijnesteijn van Coppenraet LES, van Soolingen D, Prins JM, Kuijper EJ (2011) Clinical manifestations, diagnosis, and treatment of Mycobacterium haemophilum infections. Clin Microbiol Rev 24:701-717. https://doi.org/10.1128/cmr.00020-11

3. Shah MK, Sebti A, Kiehn TE, Massarella SA, Sepkowitz KA (2001) Mycobacterium haemophilum in Immunocompromised patients. Clin Infect Dis 33:330-337. https://doi.org/10.1086/321894

4. Dawson DJ, Blacklock ZM, Kane DW (1981) Mycobacterium haemophilum causing lymphadenitis in an otherwise healthy child. Med J Aust 2:289-290

5. Minani TJ, Saubolle MA, Yu E, Sussland Z (2010) Mycobacterium haemophilum as a novel etiology of cervical lymphadenitis in an otherwise healthy adult patient. J Clin Microbiol 48:2636-2639

6. Saubolle MA, Kiehn TE, White MH, Rudinsky MF, Armstrong D (1996) Mycobacterium haemophilum: microbiology and expanding clinical and geographic spectra of disease in humans. Clin Microbiol Rev 9:435-447

7. Barr LK, Sharer LR, Khadka Kunwar E, Kapila R, Zaki SR, Drew CP, Bhatnagar J, Liu JK, Chew D (2015) Intraventricular granulomatous mass associated with Mycobacterium haemophilum: a rare central nervous system manifestation in a patient with human immunodeficiency virus infection. J Clin Neurosci 22:1057-1060. https://doi.org/10.1016/j.jocn.2014.11.036

8. Buppajarntham A, Apisarnthanarak A, Rutjanawech S, Khawcharoenporn T (2014) Central nervous system infection due to Mycobacterium haemophilum in a patient with acquired immunodeficiency syndrome. Int J STD AIDS 26:288-290. https://doi.org/10.1177/0956462414535750

9. Kleinschmidt-DeMasters B, Hawkins K, Franco-Paredes C (2018) Nontubercular mycobacterial spinal cord abscesses in an HIV plus male due to M. haemophilum. J Neuropathol Exp Neurol 6:532-532

10. Kon S, Franco-Paredes C, Hawkins KL (2020) Intramedullary spinal cord lesions in an immunocompromised host due to Mycobacterium haemophilum. IDCases 19:e00674. https://doi.org/10.1016/j.idcr.2019.e00674

11. Merkler AE, Parlitsis G, Patel S, Oliveira C, Lavi E, Schuetz A, May A, Bier D, Simpson S, Kiss S, Dinkin M (2014) Infection of the optic apparatus and hypothalamus by Mycobacterium haemophilum. Neurology 83:659-660

12. Phowthongkum P, Puengchitprapai A, Udomsantisook N, Tumwasorn S, Suankratay C (2008) Spindle cell pseudotumor of the brain associated with Mycobacterium haemophilum and Mycobacterium simiae mixed infection in a patient with AIDS: the first case report. Int J Infect Dis 12:421-424. https://doi.org/10.1016/j.ijid.2007.11.010

13. Sogani J, Ivanidze J, Phillips CD (2014) Chiasmitis caused by Mycobacterium haemophilum in an immunocompromised adult. Clin Imaging 38:727-729. doi:https://doi.org/https://doi.org/10.1016/j.clinimag.2014.02.012

14. Pai S, Esen N, Pan X, Musser JM (1997) Routine rapid Mycobacterium species assignment based on species-specific allelic variation in the 65-kilodalton heat shock protein gene (hsp65). Arch Pathol Lab Med 121:859-864

15. Horsburgh CR (1992) Epidemiology of mycobacterial diseases in AIDS. Res Microbiol 143:372-377. doi:https://doi.org/https://doi.org/10.1016/09232508(92)90048-S

16. Nookeu P, Angkasekwinai N, Foongladda S, Phoompoung P (2019) Clinical characteristics and treatment outcomes for patients infected with Mycobacterium haemophilum. Emerg Infect Dis 25:1648

17. Falkinham JO 3rd, Norton CD, LeChevallier MW (2001) Factors influencing numbers of Mycobacterium avium, Mycobacterium intracellulare, and other mycobacteria in drinking water distribution systems. Appl Environ Microbiol 67:1225-1231. https://doi.org/10.1128/aem.67.3.1225-1231.2001

18. Giulieri S, Morisod B, Edney T, Odman M, Genne D, Malinverni R, Hammann C, Musumeci E, Voide C, Greub G, Masserey E, Bille J, Cavassini M, Jaton K (2011) Outbreak of Mycobacterium haemophilum infections after permanent makeup of the eyebrows. Clin Infect Dis 52:488-491. https://doi. org/10.1093/cid/ciq191

19. Tufariello JM, Kerantzas CA, Vilcheze C, Calder RB, Nordberg EK, Fischer JA, Hartman TE, Yang E, Driscoll T, Cole LE, Sebra R, Maqbool SB, Wattam AR, Jacobs WR Jr (2015) The complete genome sequence of the emerging pathogen Mycobacterium haemophilum explains its unique culture requirements. mBio 6:e01313-e01315. https://doi.org/10. 1128/mBio.01313-15
20. Tyner HL, Wilson JW (2017) Fifteen-year clinical experience with Mycobacterium haemophilum at the Mayo Clinic: a case series. J Clin Tuberc Mycobacterial Dis 8:26-32

21. Ramya S, Devi CS, Perumal A, Asir JG, Kanungo R (2018) Detection of bacterial DNA in infected body fluids using 165 rRNA gene sequencing: evaluation as a rapid diagnostic tool. J Acad Clin Microbiol 20:92

22. Schuurman T, de Boer RF, Kooistra-Smid AM, van Zwet AA (2004) Prospective study of use of PCR amplification and sequencing of $16 \mathrm{~S}$ ribosomal DNA from cerebrospinal fluid for diagnosis of bacterial meningitis in a clinical setting. J Clin Microbiol 42:734-740. https://doi.org/10.1128/jcm. 42.2.734-740.2004

\section{Publisher's Note}

Springer Nature remains neutral with regard to jurisdictional claims in published maps and institutional affiliations.
Ready to submit your research? Choose BMC and benefit from:

- fast, convenient online submission

- thorough peer review by experienced researchers in your field

- rapid publication on acceptance

- support for research data, including large and complex data types

- gold Open Access which fosters wider collaboration and increased citations

- maximum visibility for your research: over $100 \mathrm{M}$ website views per year

At BMC, research is always in progress.

Learn more biomedcentral.com/submissions 